\title{
The determinants of goal realization and the significant role of self- efficacy in the Malaysian franchise industry
}

\author{
Nik Kamariah Nik Mat \\ Noor Hasmini Abd Ghani \\ School of Business Management, College of Business (SBMCOB) \\ Universiti Utara Malaysia, Sintok, Kedah, Malaysia \\ Fader Abdullah \\ Universiti Teknologi Mara, Arau Perlis, Malaysia \\ Rusnifaezah Musa \\ School of Business Management, College of Business (SBMCOB) \\ Universiti Utara Malaysia, Sintok, Kedah, Malaysia
}

\begin{abstract}
Keywords
Franchise, goal realization, self-efficacy, implementation desire, SEM-AMOS.
\end{abstract}

\begin{abstract}
The franchising industry in Malaysia is worth more than RM27 billion in 2017 and is rising. However, the local franchisees are still lagging behind their international players in their home country. Hence, the objective of this study is to determine the factors that lead to the innovative goal realization of the local food franchisees. This study utilizes quantitative research design by distributing 400 questionnaires consisting of measurement for seven latent variables. The instruments consist of 45 items adapted to suit the local franchise industry using a 7-point Likert scale. A response rate of $42 \%$ (169) was obtained and the data were analyzed using structural equation modeling (SEM) in AMOS. The path model demonstrates that nine relationships are significant out of twelve hypotheses examined. It signifies that to achieve goal realization, a franchisee needs to undergo a process. It started from goal desire and ends with goal realization. Self-efficacy and goal desire significantly affect goal intention which subsequently effect implementation desire. Next, implementation desire influence implementation intention and self-efficacy. Subsequently, implementation intention and self-efficacy influence plan enactment. Finally, implementation desire and plan enactment are the two significant factors influencing innovative goal realization.
\end{abstract}

Corresponding author: Nik Kamariah Nik Mat

Email addresses for corresponding author:drnikuum@gmail.com

First submission received: $11^{\text {th }}$ October 2017

Revised submission received: $14^{\text {th }}$ April 2018

Accepted: 10 $0^{\text {th }}$ May 2018

\section{Introduction}

Malaysia has projected the franchise industry to make up $9.4 \%$ of the country's gross domestic products (GDP) by 2020 from 2.2\% in 2010, to be supported by four strategic thrusts identified in the National Franchise Development Blueprint (NFDB), 2012-2016. The franchise industry generated a total revenue of RM25.6 billion in 2015, contributed by more than 400 local franchise companies. Despite the importance of franchising business in transforming Malaysian economy, there is still low goal realization among local franchisees which is evidenced from the less than $10 \%$ company value of local franchisees as compared to about $23 \%$ company value by international counterparts. Top five Malaysian Franchisors operating in Malaysia as at 31 August 2014 are Marrybrown, Secret Recipe, Old town white coffee, Paparich, and The chicken rice shop. The top five international franchisors are KFC, McDonald's, Pizza Hut, Dominos and Subway (KPDNKK, 2015). Hence this study intends to examine the factors that could lead to a better goal realization of local franchisees by borrowing from the goal realization theory developed by Dholakia, Bagozzi \& Gopinath (2007). 


\section{Review of Literature}

Goal realization (GR) is defined as the attainment of goal previously chosen by the decision maker (Bagozzi, Dholakia, \& Basuroy, 2003). While past studies had tested this model in personal goal realization, very limited studies have explored this model in franchising setting (Sarassina, 2016; Torikka, 2011; Praditbatuga, 2007). This study utilizes the goal realization theory developed by previous researcher (Dholakia, et al., 2007) - hereafter called DBG Model. According to this model, achieving goal realization is a seven-step process whereby it commences with goal desire and perceived self-efficacy, which leads to goal intention, after which it leads to implementation desire, which then leads to implementation intention. From here, the potential decision maker proceeds to plan completeness and plan enactment after which goal realization will be achieved.

Plan enactment (PE) is "the degree of successful enactment of the chosen plan" (Bagozzi, et al., 2003). There are several studies that have empirically examined the direct relationships between plan enactment and goal realization. However, the goals being observed are in non-franchise setting such as health: smoking cessation (DeVries Eggers \& Bolman, 2013), personal goals (Bagozzi, et al., 2003), snacking behavior (Tam, 2006), volitionally chosen personal goals (Dholakia, et al., 2007) and assigned goals (Bagozzi, et al., 2003). Although the results were found to be consistently significant and positive, however, there are severe shortages of such study in franchise goal achievement (Sarassina, 2016).

Goal desire (GD) is defined as the motivational state of mind of the decision maker (Bagozzi, et al., 2003). There are very limited studies investigating goal desire and goal realization in the past. The nearest construct name similar to goal desire that have been examined is 'need for achievement' (Zhenhua, Li, \& Qing, 2007), and goal frame (Lidenberg \& Steg, 2007). Their findings show equivocal results in which 'need of achievement' significantly predict goal realization while goal frame does not. Goal desire is also related to goal intention. Previous studies have evaluated the relationship between perceived desirability or goal desire and goal intention show positive and significant result (Krueger, Reilly \& Carsrud, 2000; Bagozzi, et al., 2003; Dholakia, et al., 2007). However, the majority of the existing studies only uses students as respondent (Krueger, et al., 2000; Dholakia, et al., 2007; Bagozzi, et al., 2003), and mostly focus on personal goal (Dholakia, et al., 2007; Bagozzi, et al., 2003), and the study stop at intention level (Krueger, et al., 2000; Bagozzi, et al., 2003) and in the Western setting. Thus, a study that studies real entrepreneur will be timely (Carsrud \&Brännback, 2011). and the different cultural setting of eastern country such as Malaysia might deliver different result (Hampden-Turner \& Trompenaars, 2008).

Goal intention (GI) is the intention to perform a specific behavior or a series of behavior (Gollwitzer \& Sheeran, 2006). Numerous studies have mostly studied goal intention as antecedents of behavior while only a few studies that uses goal intention as direct antecedent of goal realization (Sarassina, 2016; Dholakia, et al., 2007; Bagozzi, et al., 2003). Previous examination on this linkage has found inconsistent findings (Darmanto \& Wahyudi, 2014; DeVries, et al., 2013). Goal intention had been used in very large body of researches and had been proven as a significant and positive direct antecedent of implementation intention. A meta-analysis by (Gollwitzer \& Sheeran, 2006). showed that goal intention is indeed the direct antecedent of implementation intention in very diverse field such as collecting coupon (Aarts, Dijksterhuis \& Midden,1999), eating low fat diet (Armitage, 2004), public transportation use (Bamberg, 2000), initiation of vocational training (Brandstätter, Heimbeck, Malzacher \& Frese, 2003). prospective memory task (Einstein \& McDaniel, 2005), new year resolution (Koestner, et al., 2006) exercise (Lippke, Ziegelmann, \& Schwarzer, 2004), testicular self-examination and persistence to boring task (Milne, Orbell, \& Sheeran, 2002). Goal intention has consistently predicted implementation intention significantly and positively (Ajzen, Czasch, \& Flood, 2009; Bagozzi, et al., 2003; Bamberg, 2000). Previous finding shows the tendency of positive and significant relationship between goal intention and implementation desire (Nadkarni, 2009; Dholakia, et al., 2007; Bagozzi, et al., 2003).

Implementation desire (ID) measures how much an individual is willing to implement certain steps in achieving their desired goals (Richetin, Perugini, Adjali \& Hurling, 2008). Several studies that have studied the relationship between implementation desire and implementation intention have found significant positive linkage, but in no-franchise setting (Bagozzi, et al., 2003; Dholakia, et al., 2007; Nadkarni, 2009). However, the existing study of this relationship is still limited to personal goal (Bagozzi, et al., 2003; Dholakia, et al., 2007) health goal (DeVries, et al., 2013) and patient blood glucose (Nadkarni, 
2009). Furthermore, all studies were conducted in Western setting. Realizing that cultural differences may influence different result across different cultural setting (Hampden-Turner \& Trompenaars, 2008), thus, revisiting this relationship in eastern culture is timely. Hence, we formulated the hypotheses based on above discussion.

H1: Plan enactment is related positively to goal realization.

$\mathrm{H} 2$ : Goal desire positively influence goal realization

H3: Goal intention positively influence goal realization.

H4: Intention desire positively affect goal realization

H5: Implementation intention positively influence plan enactment.

H6: Self efficacy positively influences plan enactment

Implementation intention (II) refers to the behavior that needs to be performed in order to achieve

goal attainment (Gollwitzer \& Sheeran, 2006). Previous studies have shown inconsistent finding explaining the linkage between implementation and goal realization. Furthermore, most of the significant positive results were conducted in non-franchise setting such as entrepreneurship, health, education, social psychology, personal goal and self-management (DeVries, et al., 2013; Hechavarria, Renko \& Matthews, 2012; Stadler, Oettingen \& Gollwitzer, 2010; Adriannse, et al., 2010) while (Dholakia, et al., 2007) found insignificant result. Very limited studies were conducted in franchising. Past studies examining the relationship between implementation intention and plan enactment are scarce and unrelated to franchising setting. Although previous finding shows that there is consistent significant positive relationship between implementation intention and plan enactment, very little study can justify a similar finding in franchising (Bagozzi, et al., 2003; Tam, 2006). Furthermore, most studies only used students as respondents. Hence, the utilization of implementation intention as antecedent of plan enactment is therefore promising.

Self-efficacy (SE) refers to the beliefs in one's capabilities to organize and execute the course of action required to manage prospective situation (Bandura, 1995). The results of the relationship between self-efficacy and plan enactment are inconsistent (DeVries, et al., 2013; Bagozzi, et al., 2003). DeVries, et al., (2013) finds that the relationship is significant while Bagozzi, et al. (2003) find that it is not significant. The inconsistent result may due to differences in goal domain or maybe due to cultural differences between the Netherlands and USA (Hampden-Turner \& Trompenaars, 2008). Therefore, a study with different goal domain and different cultural setting is worth investigating. Several studies in entrepreneurship have found significant positive relationship between self-efficacy and goal intention in different parts of the world: Africa (Katono \& Heintze, 2010) Indonesia (Sihombing, 2015) Iran, Poland, Norway \& Netherlands (Moriano, et al., 2012) and Finland (Liñán, Urbano, \& Guerrero, 2011). However, the entrepreneurial studies mostly investigate students and considered failure to capture real situation of entrepreneurs. Therefore, there is a need to study this linkage with real respondents (Carsrud \&Brännback, 2011). Hence, a study that focuses on the influence of self-efficacy on goal intention using real entrepreneurs such as franchisees is timely to fill in the current vacuum. The above discussion leads to the following hypotheses;

H7: Implementation desire influence implementation intention.

H8: Goal intention positively influences implementation intention.

H9: Self efficacy positively influences implementation intention.

H10: Goal intention influence implementation desire.

H11: Goal desire positively influence goal intention.

H12: Self efficacy positively influence goal intention.

Based on the literature discussed, this study develops a research framework as in Figure 1. 


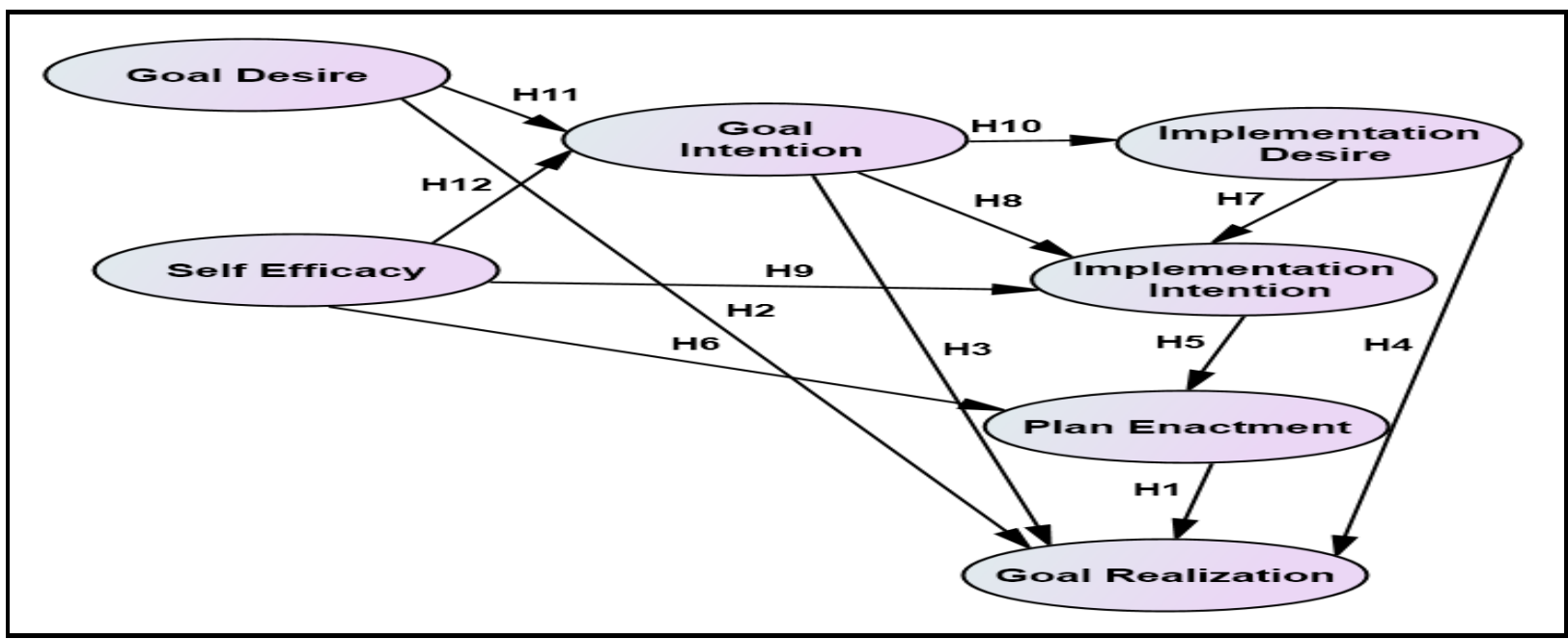

Figure 1: Research Framework

The goal realization model is called DBG model in Figure 2 (Dholakia, et al., 2007) were tested to examine the applicability of the BDB model. But in this study, Dholakia, et al. (2007) only utilize variables that were found to be significant in his previous study (Bagozzi, et al., 2003). This study only focuses on the path of goal desire to goal realization with one additional variable: self-efficacy. The finding shed the light of research where the goal that assigned goal have the same desirability to be enacted as volitionally set goal. And in the context of the goal to become franchisee, the previously set goal by the franchisees would not reduce the enactment effort to reach the assigned goal. Besides studying the difference between previously assigned goal and volitionally chosen goal, Dholakia, et al. (2007) also study the influence of plan enactment to Goal realization.

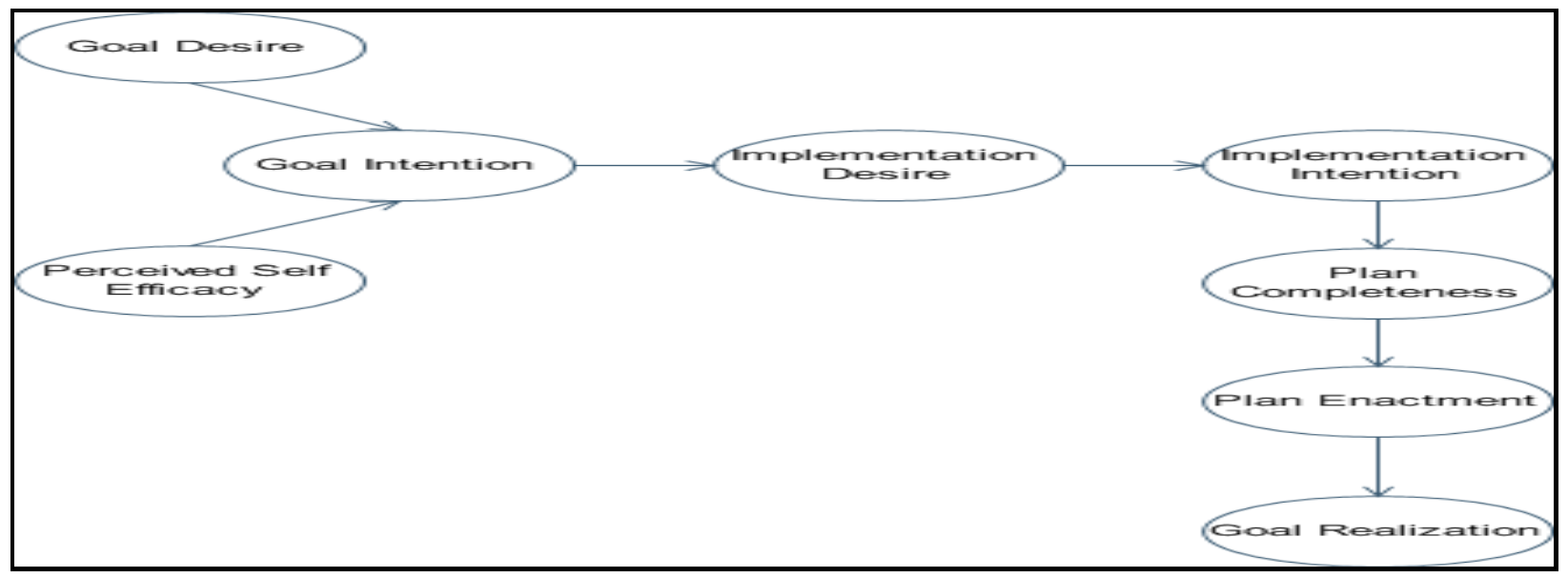

Figure 2: Underpinning Theory of goal realization

\section{Research Methodology}

This study applies the quantitative approach research design, aimed at consolidating new information and relationships between variables about the local franchisees of Malaysia.

Questionnaire design: This study employs a structured questionnaire measuring the seven constructs depicted in the research framework measuring goal realization ( 5 items); plan enactment (5 items); goal intention (7 items); goal desire (7 items), and implementation desire (5 items) were adopted from (Bagozzi, et al., 2003). Meanwhile, implementation intention (6 items) was adopted from (Webb, Sheeran \& Gollwitzer, 2005); and self-efficacy adopted from Farmer, Lines and Hamm (2011)(10 items). All questions utilized the 7-point Likert- type scale.

Sampling Method: The population used for this study is 6000 local food franchisees outlets in Malaysia (Euromonitor Passport, 2014). Based on this population frame, 400 sampling size is targeted based on Kreijie and Morgan formula table (Hair, et al., 1998). Stratified random sampling were chose 
based on strata regions. The location includes main cities in Malaysia stratified according to eight regions (Johore Bharu, Klang Valley, Ipoh, Penang, Kota Bharu, Kuala Terengganu, Kucing and Kota Kinabalu). Each of respondents were randomly selected based on the franchise database acquired from Malaysia Franchise Association.

Analysis methods: This study utilizes structural equation modeling (SEM) analysis using AMOS (Analysis of moment structures). The data were input into SPSS and a rigorous data screening was conducted to ensure data used are normalized using cdfnorm transformation. The hypothesized model is modified to fit in the generated model according to the goodness of fit indices benchmarks such as GFI $>0.90$; RMSEA $<0.08$; normed chi-square $<2 ; p$-value $>0.05$. The standardized beta estimates with $p$ value $<0.05$ are used to answer the significant hypotheses.

\section{Data Analysis and Discussion}

The responses obtained from the collection of data were 169 data sets, representing 42 percent response rate. This is expected because the franchisees are quite reluctant respondents due to interruptions to their business activities. Furthermore, the respondents are owners of franchise and expected to be very busy people. The data collected were subjected to structural equation modeling (SEM) analysis in AMOS. The demographic profile of the respondents shows that 72.5 percent of the franchisees have diploma or high school education while 27.5 percent have degrees or post graduate education. The majority ( $81 \%$ ) of the local franchisees are the Malays located in small towns (55\%). Besides, the top five brands are Marry Brown, Old town white coffee, Secret Recipe, Cool Blog and Chicken Rice Shop.

Table 1. Parameter Estimates Results of Generated Fit Structural Model

\begin{tabular}{llllllll}
\hline & & & & \\
Hypothesis & Exo & & Endo & Estimate & S.E. & C.R. & P \\
\hline H1 & PE & $<--$ & GR & 0.555 & 0.12 & 4.695 & $* * *$ \\
H2 & GD & $<--$ & GR & 0.168 & 0.117 & 1.71 & 0.087 \\
H3 & GI & $<--$ & GR & -0.239 & 0.119 & -1.861 & 0.063 \\
H4 & ID & $<--$ & GR & 0.41 & 0.091 & 4.181 & $* * *$ \\
H5 & II & $<---$ & PE & 0.632 & 0.092 & 6.383 & $* * *$ \\
H6 & SE & $<---$ & PE & 0.347 & 0.109 & 3.646 & $* * *$ \\
H7 & ID & $<--$ & II & 0.678 & 0.094 & 7.16 & $* * *$ \\
H8 & GI & $<---$ & II & -0.012 & 0.12 & -0.102 & 0.919 \\
H9 & SE & $<---$ & II & 0.237 & 0.131 & 2.244 & $0.025^{*}$ \\
H10 & GI & $<---$ & ID & 0.608 & 0.085 & 7.14 & $* * *$ \\
H11 & GD & $<---$ & GI & 0.481 & 0.115 & 5.318 & $* * *$ \\
H12 & SE & $<---$ & GI & 0.457 & 0.112 & 5.129 & $* * *$ \\
\hline
\end{tabular}

Note. Square Multiple Correlation (SMC) $/ R^{2}$ : goal realization $=0.642$, *** $p$ value $<0.001,{ }^{* *} p$ value $<0.01,{ }^{*} p$ value $<0.05$. All three levels of $p$-values are considered as significant in this study.

Figure 3 illustrates the hypothesized structural model as proposed in the research framework. It shows that the hypothesized model fails to achieve model fit since the goodness of fit indices indicates an unfit model p-value $=0.001(<0.05)$. It appears, the results of hypothesized model could not be used to generalize the population. Ultimately, the hypothesized model was fitted to generate a better fit model in Figure 4 , where $\mathrm{p}$-value $=0.72$ (indicating model fit). The results of standardized regression beta estimates, $\mathrm{SE}, \mathrm{CR}$ and p-value are presented in Table 1.

The results show that plan enactment positively influence goal realization $(B=0.55 ; C R=4.695$; $\mathrm{p}<0.001$ ), thus supporting hypothesis H1. Similar finding was found by previous researches (DeVries, et al., 2013; Bagozzi, et al., 2003; Tam, 2006; Dholakia, et al., 2007). Similarly, implementation desire positively influences goal realization $(\mathrm{B}=0.41 ; \mathrm{CR}=4.181 ; \mathrm{p}<0.001)$, again supporting hypothesis $\mathrm{H} 4$. Goal desire and goal intention do not influence goal realization significantly, thus, $\mathrm{H} 2$ and $\mathrm{H} 3$ are not supported. 
Additionally, both implementation intention and self-efficacy positively influence plan enactment, supporting $\mathrm{H} 5$ and H6. Implementation desire and self-efficacy also show a significant positive influence on implementation intention, hence H7 and H9 are supported. Goal desire however, do not influence implementation intention, indicating a non-support for $\mathrm{H} 8$.

Furthermore, goal intention is found to have a significant positive influence on implementation desire. Likewise, goal desire and self-efficacy has a positive significant influence on goal intention hence supporting H11 and H12. To summarize, nine linkages are supported while 3 linkages are not supported. The squared multiple correlation or regression squared explained 64.2 percent variance in goal realization.

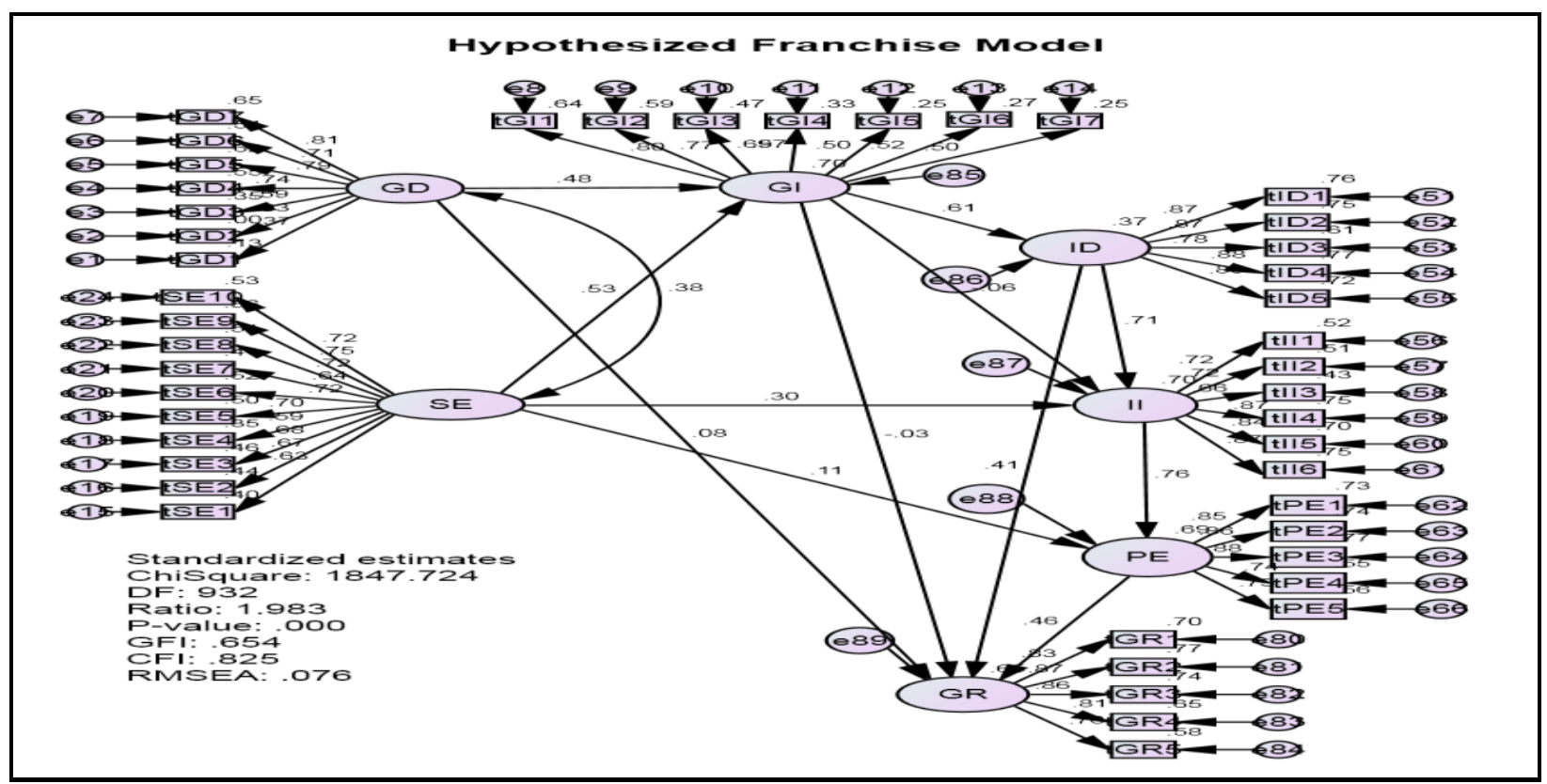

Figure 3: Hypothesized Structural Model

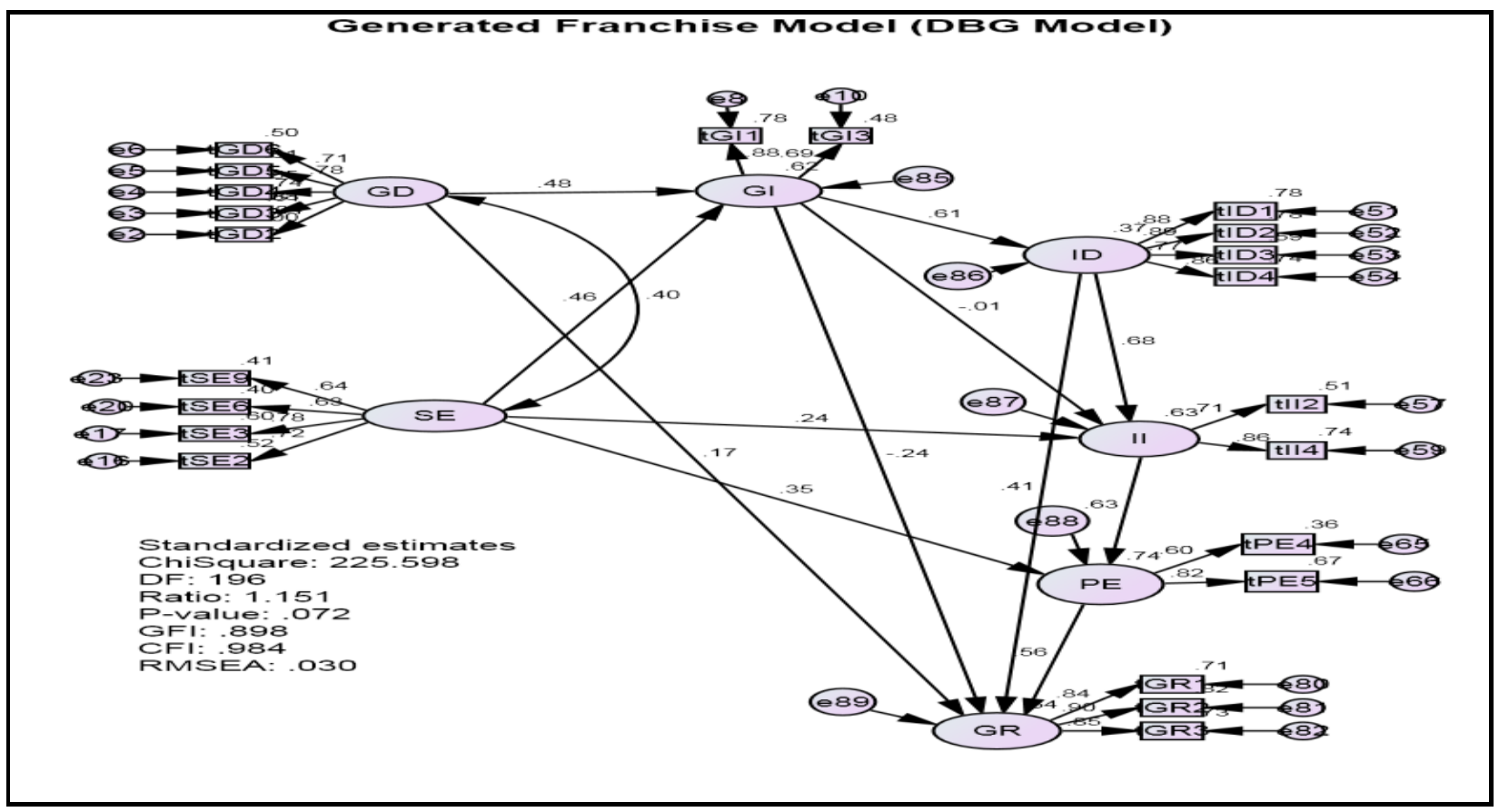

Figure 4: Generated Fit Structural Model

www.jbrmr.com A Journal of the Academy of Business and Retail Management (ABRM) 


\section{Conclusion}

This study has achieved its objective in investigating the factors that influence the goal realization of incumbent local franchisees. It was found that plan enactment and implementation desire are very important predictors of goal realization of franchisees. For franchisees to succeed in the commencement stage, it is very necessary for the franchisees to have goal desire and self-efficacy. Self-efficacy is an important ingredient for plan enactment, implementation desire and goal intention. Desire to excel and having innovative knowledge (self-efficacy) in the field that they are going into is detrimental for success. Once these two skills are in place, they can effortlessly proceed to the implementation stage. This study implies that self-efficacy is a very vital element to progress. Goals of becoming a successful franchise can be realized as proven by the increased of local Malaysian franchisors going abroad into the international arena.

\section{References}

Aarts, H., Dijksterhuis, A.P. and Midden, C., (1999). To plan or not to plan? Goal achievement or interrupting the performance of mundane behaviors. European Journal of Social Psychology, 29(8), pp.971-979.

Adriaanse, M.A., Oettingen, G., Gollwitzer, P.M., Hennes, E.P., De Ridder, D.T. and De Wit, J.B., (2010). When planning is not enough: Fighting unhealthy snacking habits by mental contrasting with implementation intentions (MCII). European Journal of Social Psychology, 40(7), pp.1277-1293.

Ajzen, I., Czasch, C. and Flood, M.G., (2009). From intentions to behavior: Implementation intention, commitment, and conscientiousness. Journal of Applied Social Psychology, 39(6), pp.1356-1372.

Armitage, C.J., (2004). Evidence that implementation intentions reduce dietary fat intake: A randomized trial. Health Psychology, 23(3), p.319.

Bagozzi, R.P., Dholakia, U.M. and Basuroy, S., (2003). How effortful decisions get enacted: The motivating role of decision processes, desires, and anticipated emotions. Journal of Behavioral Decision Making, 16(4), pp.273-295.

Bamberg, S., (2000). The promotion of new behavior by forming an implementation intention: Results of a field experiment in the domain of travel mode choice. Journal of Applied Social Psychology, 30(9), pp.1903-1922.

Bandura. A (1995). Self-efficacy in changing societies. Cambridge University Press

Brandstätter, V., Heimbeck, D., Malzacher, J. and Frese, M., (2003). Goals need implementation intentions: The model of action phases tested in the applied setting of continuing education. European Journal of Work and Organizational Psychology, 12(1), pp.37-59.

Carsrud, A. and Brännback, M., (2011). Entrepreneurial motivations: what do we still need to know?. Journal of Small Business Management, 49(1), pp.9-26.

Darmanto, S. and Wahyudi, S., (2014). Developing Intention and Entrepreneurial Behavior Through the Mediating Role of Entrepreneurial Self Efficacy Maturity (An Empirical Study on University Students in Semarang, Indonesia). Available at Social Science Research Network, 235090. Papers.ssrn.com. 1-29.

de Vries, H., Eggers, S.M. and Bolman, C., (2013). The role of action planning and plan enactment for smoking cessation. BMC Public Health, 13(1), p.393.

Einstein, G.O. and McDaniel, M.A., (2005). Prospective memory: Multiple retrieval processes. Current Directions in Psychological Science, 14(6), pp.286-290.

Euromonitor Passport. (2014). Consumer food service in Malaysia. [ONLINE] Available at:

http://go.euromonitor.com/passport.html. [Accessed 6 October 2014].

Farmer, T.W., Lines, M.M. and Hamm, J.V., (2011). Revealing the invisible hand: The role of teachers in children's peer experiences. Journal of Applied Developmental Psychology, 32(5), pp.247-256.

Gollwitzer, P.M. and Sheeran, P., (2006). Implementation intentions and goal achievement: A meta-analysis of effects and processes. Advances in experimental social psychology, 38, pp.69-119.Available

http://doi.org/10.1016/S0065-2601(06)38002-1.

Hair, J.F., Black, W.C., Babin, B.J., Anderson, R.E. and Tatham, R.L., (1998). Multivariate data analysis (Vol. 5, No. 3, pp. 207-219). Upper Saddle River, NJ: Prentice hall.

Hampden-Turner, C.M. and Trompenaars, F., (2008). Building cross-cultural competence: How to create wealth from conflicting values. Yale University Press.

Hechavarria, D.M., Renko, M. and Matthews, C.H., (2012). The nascent entrepreneurship hub: goals, entrepreneurial self-efficacy and start-up outcomes. Small Business Economics, 39(3), pp.685-701.available

http://doi.org/10.1007/s11187-011-9355-2.

Katono, I.W. and Heintze, A., (2010). Environmental factors and graduate start up in Uganda.Paper presented at the Conference on Entrepreneurship in Africa. New York: Whitman School of Management, Syracuse University. 
Koestner, R., Horberg, E.J., Gaudreau, P., Powers, T., Di Dio, P., Bryan, C., Jochum, R. and Salter, N., (2006). Bolstering implementation plans for the long haul: The benefits of simultaneously boosting self-concordance or selfefficacy. Personality and Social Psychology Bulletin, 32(11), pp.1547-1558. Available at

http:/ / doi.org/10.1177/0146167206291782.

Dholakia, U.M., Bagozzi, R.P. and Gopinath, M., (2007). How formulating implementation plans and remembering past actions facilitate the enactment of effortful decisions. Journal of Behavioral Decision Making, 20(4), pp.343364.

Krueger Jr, N.F., Reilly, M.D. and Carsrud, A.L., (2000). Competing models of entrepreneurial intentions. Journal of business venturing, 15(5-6), pp.411-432.

Liñán, F., Urbano, D. and Guerrero, M., (2011). Regional variations in entrepreneurial cognitions: Start-up intentions of university students in Spain. Entrepreneurship and Regional Development, 23(3-4), pp.187-215.

Lindenberg, S. and Steg, L., (2007). Normative, gain and hedonic goal frames guiding environmental behavior. Journal of Social issues, 63(1), pp.117-137.Available at

http://www.rug.nl/staff/e.m.steg/lindenbergsteggoalframing.pdf

Lippke, S., Ziegelmann, J.P. and Schwarzer, R., (2004). Behavioral intentions and action plans promote physical exercise: A longitudinal study with orthopedic rehabilitation patients. Journal of Sport and Exercise Psychology, 26(3), pp.470-483.

Milne, S., Orbell, S. and Sheeran, P., (2002). Combining motivational and volitional interventions to promote exercise participation: Protection motivation theory and implementation intentions. British journal of health psychology, 7(2), pp.163-184.

Moriano, J.A., Gorgievski, M., Laguna, M., Stephan, U. and Zarafshani, K., (2012). A cross-cultural approach to understanding entrepreneurial intention. Journal of career development, 39(2), pp.162-185.

Nadkarni, A., (2009). Implementation plans and self-monitoring of blood glucose in diabetics (Doctoral dissertation, University of Michigan).

Praditbatuga, P., (2007). Reaching the decision to purchase a franchise in Thailand (Doctoral dissertation, University of South Australia).

Richetin, J., Perugini, M., Adjali, I. and Hurling, R., (2008). Comparing leading theoretical models of behavioral predictions and post-behavior evaluations. Psychology $\mathcal{E}$ Marketing, 25(12), pp.1131-1150.

Sarassina, R.R.F., (2016). The relationship between self efficacy and goal realization in Indonesia foodservice industry (Doctoral dissertation, Universiti Utara Malaysia).

Sheeran, P., Webb, T.L. and Gollwitzer, P.M., (2005). The interplay between goal intentions and implementation intentions. Personality and Social Psychology Bulletin, 31(1), pp.87-98.

Sihombing, S.O., (2015). Comparing entrepreneurship intention: A multigroup structural equation modeling approach. International Research Journal of Business Studies, 5(1).

Stadler, G., Oettingen, G. and Gollwitzer, P.M., (2010). Intervention effects of information and self-regulation on eating fruits and vegetables over two years. Health Psychology, 29(3), p.274.

Tam, W.Y.L., (2006). Goal pursuit is more than planning: the moderating role of regulatory fit (Doctoral dissertation, Texas A\&M University).

Torikka, J., (2011). Exploring Various Entrepreneurial Processes of the Franchisee Training Program Graduates: Empirical Evidence from a Longitudinal Study. In The Fifth International Conference on Economics and Management of Networks. Limassol, Cyprus: EMNET.

Zhen-hua, L., Li, C. and Qing, L., (2007), August. Study on the Relationships among Entrepreneur Traits, Goal Orientation and New Venture Performance. In Management Science and Engineering, 2007. ICMSE 2007. International Conference on (pp. 669-674). IEEE. 